\title{
A Historical Review on Antibiotic Resistance of Foodborne Campylobacter
}

\author{
Yichao Yang ${ }^{1 \neq}$, Kristina M. Feye ${ }^{2 t \neq}$, Zhaohao Shi ${ }^{3}$, Hilary O. Pavlidis ${ }^{4}$, Michael Kogut ${ }^{2}$, \\ Amanda J. Ashworth ${ }^{5}$ and Steven C. Ricke ${ }^{2 *}$ \\ ${ }^{1}$ Department of Poultry Science, University of Arkansas Fayetteville, Fayetteville, AR, United States, ${ }^{2}$ Southern Plains \\ Agricultural Research Center, Agricultural Research Service, United States Department of Agriculture, College Station, TX, \\ United States, ${ }^{3}$ Center of Food Safety, Department of Food Science, University of Arkansas, Fayetteville, AR, United States, \\ ${ }^{4}$ Diamond V, Cedar Rapids, IA, United States, ${ }^{5}$ Poultry Production and Product Safety Research Unit (USDA-ARS), \\ Fayetteville, AR, United States
}

Campylobacter is one of the most commonly reported foodborne human bacterial gastrointestinal pathogens. Campylobacter is the etiological agent of campylobacteriosis, which is generally a self-limited illness and therefore does not require treatment. However, when patients are immunocompromised or have other co-morbidities, antimicrobial treatment may be necessary for clinical treatment of campylobacteriosis, macrolides and fluoroquinolones are the drugs of choices. However, the increase in antimicrobial resistance of Campylobacter to clinically important antibiotics may become insurmountable. Because of the transmission between poultry and humans, the poultry industry must now allocate resources to address the problem by reducing Campylobacter as well as antimicrobial use, which may reduce resistance. This review will focus on the incidence of antibioticresistant Campylobacter in poultry, the clinical consequences of this resistance, and the mechanisms of antibiotic resistance associated with Campylobacter.

Keywords: Campylobacter, antibiotic resistance, macrolide, fluoroquinolone resistance, historical review

\section{THE IMPORTANCE OF ANTIBIOTIC-RESISTANT CAMPYLOBACTER}

Campylobacteriosis is usually a self-limited illness, and patients with prolonged symptomology are usually placed on a macrolide or fluoroquinolone antibiotic regimen (Salazar-Lindo et al., 1986; Allos and Blaser, 2010). However, antibiotic resistance of Campylobacter to these important classes of antibiotics, especially fluoroquinolones, is on the rise (US Food and Drug Administration, 2014; Bolinger et al., 2018). Resistance in two important Anti-Campylobacter antibiotics, azithromycin (macrolide) and ciprofloxacin (fluoroquinolone), has increased, resulting in approximately 310,000 cases of potentially untreatable infections, leading to 28 deaths in the United States annually (CDC, 2019).

The rise in antibiotic resistance has been geographically heterologous, with trends in both good and bad antibiotic stewardship mirrored in the agricultural and private sector. Information learned through epidemiological studies in higher income countries is targeted toward stopping resistance. Specifically, the antibiotic stewardship programs like the National Healthcare Safety Network, Gonococcal Isolate Surveillance Program, National Tuberculosis Surveillance System, 
and the Emerging Infections Program have all increased awareness of the prescription behavior, patient compliance, and resistance pattern of important clinical pathogens (Ventola, 2015a,b). Many of these programs have targeted practitioners to stop over-prescribing antibiotics. Instead, data have directly resulted in a more tuned regimen program for multiple classes of clinically important antibiotics and led to improve treatment success (Fridkin et al., 2014; Ventola, 2015a,b). Specific to food, the National Antimicrobial Resistance Monitoring System was established in 1996. This program distributes information and conducts research on foodborne pathogens from retail meat and the risk may or may not pose to the community as a whole (Zhao et al., 2006; Ventola, 2015a,b). The World Health Organization has had additional resolutions to improve antibiotic stewardship as the European Union and other groups worldwide (Ventola, 2015a,b). In more developed countries, organizations track the spread of antibiotic-resistant foodborne pathogens, which in turn enable regulatory agencies to change management strategies. This awareness has brought about changes that may ultimately reduce the risk of antibiotic resistance.

While antibiotic stewardship is still a challenge in high income countries, it is not the same obstacle as what is faced in lower to middle income countries. In these countries, agriculture is exploding, and there are very few, if any, regulations on the market to control the use of antibiotics. As these countries also typically have high incidence of diarrheal disease that impacts growth and development as well as reduces vaccine efficiency, the rise in any antibiotic resistance is alarming (McCormick and Lang, 2016). In particular, countries such as Brazil, Russia, India, China, and South Africa (BRICS) require antibiotics to meet the agricultural paradigm in place (Van Boeckel et al., 2014).

In the BRICS countries, poor hygiene, lack of access to potable water, and the absolutely uncontrolled use of antibiotics all contribute to this issue of spreading disease and rise in resistance (Van Boeckel et al., 2014; Frost et al., 2019). For instance, in India, Campylobacter isolates are often multipledrug resistant and have phenotypic resistance to ciprofloxacin, tetracycline, furazolidone, ampicillin, gentamicin, and erythromycin (Jain et al., 2005). In Central America, trends hold true as well, with antibiotic-resistant Campylobacter on the rise (Toledo et al., 2018).

Besides reducing the treatment failures for diarrheal diseases in low income countries, preventing the rise in antibiotic-resistant Campylobacter is essential as certain populations that are more at risk for severe complications. These populations, such as the immunocompromised or the elderly, will likely be placed on antibiotic regimens in order to prevent bacteremia and sequelae. Specifically, HIV patients are particularly vulnerable as infections can be intractable with bacteremia, ultimately requiring macrolide or fluoroquinolone therapy (Hussein et al., 2016). Another potential outcome of campylobacteriosis includes when Campylobacter disseminates to the periphery and causes profound disease. Campylobacter fetus, a rare and animal associated Campylobacter species epithet, causes spondylodiscitis in HIV and aged patients that commonly have other comorbidities (diabetes mellitus), where common therapeutics are not effective
(Olaiya et al., 2018). Therefore, antibiotic-resistant strains of Campylobacter are absolutely problematic clinically as treatment resistance could have significant consequences for immunocompromised patients. As a result, understanding how resistance occurs historically is important in order to potentially find novel patterns and lessons in controlling Campylobacter.

A controversial avenue for the introduction of antibioticresistant Campylobacter strains to humans is through the consumption of meat, including poultry (Thakur et al., 2010; Barton, 2014; US Food and Drug Administration, 2014; Mäesaar et al., 2016). Campylobacter is present as a commensal organism in the gastrointestinal tracts (GITs) of poultry and can be antibiotic resistant (Zhao et al., 2010; Kojima et al., 2015; Ohishi et al., 2017; Raeisi et al., 2017). A Polish study indicated that as many as $94.4 \%$ of Campylobacter jejuni isolated from chicken are resistant to at least one class of antibiotic (Wieczorek et al., 2017). However, the link between agriculture and human clinical isolates of Campylobacter remains controversial. This review will focus on the mechanisms associated with antibiotic resistance, the controversial link between the use of antibiotics in agriculture and clinical resistance, and the current antibiotics available as well as the challenges faced with the ever-present rise in antibiotic-resistant isolates.

\section{ANTIBIOTIC RESISTANCE MECHANISMS}

Antibiotics inhibit the growth and proliferation of microorganisms by binding to a specific target central to the microbial molecular biology and inhibiting the targets normal homeostatic activity or otherwise preventing the activity of an antibiotic. These effects can result in either bacteriostatic (cessation of replication) or bactericidal (killing) effects on the microorganism. There are four common mechanisms associated with antibiotic resistance: alteration of the antibiotic target, inactivation of the drug, decreasing membrane permeability, and the expression of antimicrobial efflux pumps (Iovine, 2013). In Campylobacter, mechanisms of antibiotic resistance are no different and are on occasion multimodal.

One of the most common mechanisms associated with antibiotic resistance is the ability of microorganisms to alter their membrane permeability, which ultimately prevents diffusion of the antibiotic into the intracellular environment. Porins are transmembrane proteins that create molecular pores allowing for the diffusion of chemical compounds that otherwise cannot cross the cell membrane, including antibiotics, into the periplasmic and intracellular environment (Galdiero et al., 2012). Campylobacter reduces membrane permeability via changing the expression of porins (Page et al., 1989; Pumbwe et al., 2004). In many instances, the natural and unique porins expressed by Campylobacter naturally prevent the entry of most antibiotics with molecular weights greater than 360 KDas (Page et al., 1989). By altering porin expression pattern, Campylobacter can reduce antibiotic diffusion to target within the intracellular and periplasmic space.

Another common mechanism used by Campylobacter for resistance is the expression of efflux pumps, which in many 
cases result in multidrug-resistant phenotypes. Efflux pumps can be expressed by both Gram-positive and Gram-negative prokaryotes and actively transport structurally variable molecules like antibiotics from the periplasmic or cytoplasmic space to the external environment of the cell (Pagès and Amaral, 2009; Nikaido and Pagès, 2012; Handzlik et al., 2013; Blair et al., 2014; Yao et al., 2016). An example of this includes the efflux pumps used by Campylobacter that removes the aminoglycosides from the intracellular space, preventing the antibiotic from reaching the ribosome and exerting its effects. Potential novel approaches to combating this kind of resistance include potentiators that act as efflux pump antagonist, which ultimately shuts down resistance (Mamelli et al., 2003; Payot et al., 2004). Efflux pumps are especially concerning as they are not specific and may successfully efflux multiple classes of antibiotics. Yao et al. (2016) found that the emergence of a super efflux pump variant, named $R E-C m e A B C$, directly confers multidrug resistance in Campylobacter as it can non-specifically efflux multiple classes of antibiotics. $R E-C m e A B C$ is a particularly dangerous genetic element as it is encoded in a plasmid and subject to horizontal transfer.

Mutations in the target site reduce affinity and avidity for the antibiotic, which ultimately makes that class of antibiotics ineffective (Vetting et al., 2011). For example, fluoroquinolone resistance is due to a point mutation in the topoisomerase site where the antibiotic typically binds and renders it ineffective. Point mutations occur naturally as a consequence of normal biological replication and can be favored or disfavored by environmental conditions. By changing that target site, the point mutation reduces the binding affinity of the fluoroquinolone (Ling et al., 2003). In environments where antibiotics are non-existent, resistant point mutations are not likely a favored or even result in a neutral mutation. However, if antibiotics are present, the surviving bacterial progeny must confer that mutation for resistance and selective pressure results in the mutation becoming dominant (Ling et al., 2003). Additionally, the biotransformation of an antibiotic by the bacteria intracellularly can also render it ineffective. Bacterial enzymes in the bacteria modify side chains of chemical groups on the antibiotic, which consequentially reduce antibiotic-binding affinity to the target site. A classic example of this important mechanism occurs in aminoglycoside antibiotics, which have numerous hydroxyl and amide groups that are vulnerable to modification once in bacterial systems (Norris and Serpersu, 2013). Once modified, the aminoglycosides are ineffective.

The rise in multiple antibiotic-resistant Campylobacter is mechanistically multimodal. Numerous studies point to multimodal resistance becoming an important component of Campylobacter drug resistance. Hao et al. (2016) found that C. jejuni 1655 had several mutations at different target sties for antibiotics, including Thr-86-Ile mutation in gyrA and the A2075G mutation in 23S rRNA, tetO, aphA, and aadE genes. Additionally, C. jejuni 1655 carried a pTet plasmid. All together, these mutations and plasmids result in a multidrug resistant phenotype to fluoroquinolone, macrolide, tetracycline, and aminoglycoside classes of antibiotics. Therefore, identifying one mechanism of resistance as the resistance "smoking gun" is not likely. Clinically, data indicates that Campylobacter should be subjected to antibiograms prior to the initiation of clinical therapeutic regimens to select antibiotics; the pathogen is susceptible in order to ensure that positive therapeutic outcomes are possible.

\section{AGRICULTURE, ANTIBIOTICS, AND CAMPYLOBACTER}

Significant press and public attention have, likely unfairly, pointed to the agricultural industry as the root cause of antibiotic resistance. However, this is still a controversial notion, with data resulting from multiple studies ultimately being non-conclusive. Multiple studies have been conducted to determine whether or not this link is real. Ultimately, this may be a case of correlation not indicating causation. While the rise in resistance in the clinical sector is mirrored in the agricultural sector, these may be very independent events or perhaps existing in a gray area. The judicious use of antibiotics as a whole may ultimately combat antibiotic resistance.

In order to determine if there was a link between antibioticresistant Campylobacter in poultry with human campylobacteriosis, a study was conducted that isolated Campylobacter strains from poultry and human clinical campylobacteriosis samples (Wieczorek et al., 2018). While some correlations existed, the link was neither direct nor concrete and remains controversial. Additionally, Silva et al. (2016) found that there is no relationship between Campylobacter isolated from human and poultry sources based on pulse field gel electrophoresis analysis. More research is needed to fill the gap between animal use antibiotics and human infection of antibiotic-resistant pathogens.

The paralleled rise in resistance is illustrated by the rise of quinolone-resistant strains in the veterinary and clinical setting. It is true that in the early 1990s, Endtz et al. (1991) found a rise in resistant strains isolated from poultry products from 0 to $14 \%$ between 1982 and 1989. Correspondingly, quinolone-resistant Campylobacter isolates increased from 0 to $11 \%$ isolated from human sources. In order to determine if agricultural isolates impacted human disease outcomes, Zhao et al. (2015) used pulsed-field gel electrophoresis (PFGE) to subtype Campylobacter isolates from humans and retail poultry and observed that isolates between the two sets displayed the same resistance phenotypes and PFGE patterns. Data indicated that the human isolates were likely linked to the contaminated poultry products. However, this is not entirely correlative and the exposure of humans to resistant Campylobacter does not come without its own nuances. Zhao et al. (2015) also observed that human isolates of Campylobacter tended to be more genetically diverse and resistant than the retail chicken isolates. This amplification of drug resistance in clinical patients may be due to the horizontal transfer of mobile genetic elements encoding antibiotic resistance in the human gastrointestinal tract (Barnes et al., 1972; Eckburg et al., 2005). 
In order for causation to be correlative, a direct link must be established and consistent between agriculture and clinical isolates, which remains to be the case with Campylobacter. The missing link likely speaks to the complexities associated with mobile genetic elements making that direct link unlikely or that the correlation ultimately does not mean causation. Some models have shown that antibiotics fed to food animals present a low risk of clinical treatment failure associated with antibiotic resistance. For example, Hurd et al. (2004) conducted a risk assessment modeling the effects of tylosin and tilmicosin, two macrolide antibiotics, on Campylobacter spp. and E. faecium. The scientists administered both types of veterinary antibiotics to swine, cattle, or poultry for therapeutic, prophylactic, and growth promotion. The antimicrobial resistance determinant was considered the most likely hazard factor for causing human illness, which is supported by U.S. Food and Drug Administration's Center of Veterinary Medicine. This farm-to-patient risk assessment model indicated that the use of macrolides resulted in less than 1 in 10 million rate of failure in treating Campylobacter with these two antibiotics. While resistance is a problem in both sectors, the common use of macrolides used in food animals does not impact antibiotic resistance in human campylobacteriosis.

\section{ANTIBIOTICS USED TO TREAT CAMPYLOBACTERIOSIS IN THE CLINICAL SETTING}

The CDC has recommended treatment regimens be initiated for Campylobacter if the patients have weakened immune systems or are experiencing profound effects. Commonly, macrolides and fluoroquinolones are prescribed with macrolides being preferred due to their low resistance rate (CDC, 2019). It has been documented that there are a greater frequency in identifying fluoroquinolone-resistant isolates compared to macrolide-resistant Campylobacter isolates. That may be due to the mutation frequency of the $50 \mathrm{~S}$ ribosomal subunit that confers resistance occurring in approximately 10 mutations per Campylobacter cell per generation. The mutation frequency for the $50 \mathrm{~S}$ ribosomal subunit is 10,000 -fold lower than the mutation frequency of the gyrase and topoisomerase genes that confer fluoroquinolone resistance (Yan et al., 2006; Lin et al., 2007). The increased rate in mutation frequency likely corresponds to the rise in ciprofloxacin-resistant isolates Campylobacter, which was from $13 \%$ in 1997 to $19 \%$ in 2001 (Gupta et al., 2004). This is compared to the steady prevalence of $2 \%$ erythromycin, a macrolide, resistant positive isolates of Campylobacter during the same time period (Gupta et al., 2004). This trend has continued through time as currently the prevalence of fluoroquinolone resistance is $35.4 \%$ in C. jejuni and $74.4 \%$ in Campylobacter coli in the United States (Tang et al., 2017).

\section{MACROLIDES}

A course of the macrolide azithromycin is the gold standard chemotherapeutic regimen to treat Campylobacter infections, which effectively reduces bacterial shedding and the length of the illness (Kuschner et al., 1995). The breakpoint concentration associated with azithromycin indicates that 30 to $500 / \mathrm{d}$ for 3 days of azithromycin was effective for the eradication of Campylobacter and acceleration of a patient's recovery time (Kuschner et al., 1995; Vukelic et al., 2010). This, as well as the low incidence of natural resistance, has led to azithromycin being the drug of choice (DuPont, 2007).

Another option for therapeutic regimens in clinical medicine includes the use of erythromycin (Guerrant et al., 2001). Efficacy is lost when the antibiotic regimen is not started at the onset of symptoms and may require prolonged treatment (Guerrant et al., 2001). Advantages of using erythromycin include the low frequency of natural resistance of Campylobacter to erythromycin (Smith et al., 1999; Bardon et al., 2009), with antibiogram analysis of 1,808 isolates from Finnish patients between 2003 and 2005 reporting a resistance prevalence to erythromycin at $1.1 \%$ (Lehtopolku et al., 2010). Clindamycin is a lincomycin antibiotic, and Wagner et al. (2003) first proposed this as a potential therapeutic for campylobacteriosis. This alternative was evaluated by determining the minimum inhibitory concentration for five common antibiotics. The researchers observed that only $2 \%$ of the Campylobacter isolates were resistant to clindamycin, while greater than $45 \%$ of isolates exhibited resistance against four fluoroquinolone antibiotics tested (Wagner et al., 2003).

\section{FLUOROQUINOLONES}

Fluoroquinolones may be used to treat Campylobacter but are problematic due to the resistance profile of clinical Campylobacter isolates (Nord and Edlund, 1991). The clinical isolates associated with active campylobacteriosis exhibit greater frequencies of quinolone resistance, increasing as much as 20-fold in the 1990s in Sweden (Wretlind et al., 1992; Gibreel et al., 1998). As with macrolide resistance, fluoroquinolone resistance is naturally occurring as a point mutation, ultimately leading to treatment failure and symptomatic relapse (Segreti et al., 1992; Sanders et al., 2007). A classic example of this issue is norfloxacin, fluoroquinolone widely used to treat enteric infections (Sjögren et al., 1997). Epidemiological evidence indicates that resistance can occur within 1 day of therapy (Sjögren et al., 1997). In fact, resistance to multiple fluoroquinolones exhibits a sharp increase in Campylobacter isolates, such as the rise of nalidixic acid resistance from $8.2 \%$ in 1990 to $26.3 \%$ in 2004 (Gallay et al., 2007), and a similar trend of quinolone resistance occurred in Germany (Luber et al., 2003).

There are promising fluoroquinolones for use in the clinical setting, yet mounting resistance continues to be a significant theme in the historical perspective associated with Campylobacter fluoroquinolone resistance. For instance, moxifloxacin is a fourth-generation synthetic fluoroquinolone that effectively kills Campylobacter and is difficult to mount resistance toward, as compared to ciprofloxacin (Wagner et al., 2003). Additionally, the use of levofloxacin in clinical cases of campylobacteriosis 
is promising (de la Cabada Bauche and DuPont, 2011). The effectiveness of a single dose treatment of $500 \mathrm{mg} / \mathrm{d}$ of levofloxacin is similar to $1,000 \mathrm{mg} / \mathrm{d}$ of azithromycin but with fewer side effects (Sanders et al., 2007). However, as with most fluoroquinolones, resistance has been observed when compared with azithromycin (Sanders et al., 2007).

Resistance against other fluoroquinolones has been widespread. A common fluoroquinolone of choice for medical practitioners, ciprofloxacin, has been reported in developing countries with levels ranging from 30 to greater than $84 \%$ (Hoge et al., 1998; Pandey et al., 2010; Meng et al., 2011). As with other fluoroquinolones, the frequency of isolating ciprofloxacin-resistant strains of Campylobacter is rising. In Peru, Pollett et al. (2012) observed that between 2001 and 2010, the prevalence of ciprofloxacin-resistant Campylobacter isolates rose from 73.1 to $89.9 \%$ in the area of Lima and from 24.1 to $48.9 \%$ in the Iquitos region. Similar to the clinical setting, an increased prevalence of fluoroquinoloneresistant Campylobacter strains has been recovered from food animals in developed countries (Taylor et al., 2008). Nannapaneni et al. (2005) isolated ciprofloxacin-resistant Campylobacter isolates from retail raw chicken carcasses in the United States with numbers ranging from 57\% in 2001 to $96 \%$ in 2003 . This is likely due to the relationship developing countries have with antibiotics, which ultimately results in poor antibiotic stewardship and an ultimately significant increase in antibiotic resistance. Therefore, increase in both clinical and veterinary isolates of Campylobacter in the developing world is anecdotal of a larger problem in countries where the use of antibiotics in both independent settings, the clinical and the veterinary, is poorly controlled and executed.

\section{MODELS FOR CONTROLLING CAMPYLOBACTER}

The intensive use of antibiotics has been suggested to have an increased number of resistant strains of mutants and a decreased effectiveness of antibiotics (Wegener, 2003; Ventola, 2015a,b). The World Health Organization (WHO) has concluded that increases in antibiotic resistance represent a considerable, worldwide threat to public health (WHO, 2014). In order to attempt to preserve the efficacy of clinical antibiotics, the European Union banned the use of clinical antibiotics for growth promotion in 1999 (Casewell et al., 2003). In the United States, the Institute of Medicine recommend to reduce or eliminate the use of antibiotics in feed in 1980 and 1989, and also it was supported by a Council for Agricultural Science and Technology (1981) and a Committee on Drug Use in Food Animals Panel on Animal Health, Food Safety, and Public Health (1998). The Veterinary Feed Directive was recently implemented in the United States to limit the use of human clinical antibiotics as well as provide stricter guidelines for the use of antibiotics in food animals and is viewed as the first step to solving a significant veterinary and human clinical problem (Veterinary Feed Directive (VFD), 2017).
TABLE 1 | Veterinary feed directive antibiotics.

\begin{tabular}{lll}
\hline & $\begin{array}{l}\text { Medically } \\
\text { important drugs }\end{array}$ & $\begin{array}{l}\text { Non-medically } \\
\text { important drugs }\end{array}$ \\
\hline Therapeutic uses & $\begin{array}{l}\text { Allow under veterinary } \\
\text { supervision }\end{array}$ & $\begin{array}{l}\text { Allow under veterinary } \\
\text { supervision }\end{array}$ \\
Production use & $\begin{array}{l}\text { Nollowed } \\
\text { Drugs }\end{array}$ & $\begin{array}{l}\text { 1. Penicillin } \\
\text { 2. Cephallowermycin }\end{array}$ \\
& $\begin{array}{l}\text { 2. Cainolones } \\
\text { 3. Fluoroquinolones }\end{array}$ & 3. lonophores \\
& 4. Pleuromutilin \\
& 5. Tetracyclines & 5. Polypeptides \\
6. Macrolides & \\
7. Sulfas & \\
8. Glycopeptides & \\
\hline
\end{tabular}

However, despite the regulations, it is still under debate about the relationship between resistance microorganisms selected when an antibiotic was used as the growth promoter in food animals and the antibiotic-resistant infections in humans (Phillips et al., 2004; Vaughn and Copeland, 2004). At the time of increasing concern about the spread of antibiotic resistance pathogens in humans, U.S. Food and Drug Administration initiated the Veterinary Feed Directive (VFD), which requires a prescription from a veterinarian to use medically important antibiotics in infected animals. These medically important antibiotics are not allowed to be used as growth promoters. The regulation information has been listed in Table 1.

As with other bacteria, the use of the correct antibiotic with the correct species epithet is important and is a tenant of good antimicrobial stewardship. When analyzing antibioticresistant isolates of Campylobacter isolated from live broilers, Li et al. (2017) reported that C. coli exhibited significantly greater prevalence of antibiotic resistance than $C$. jejuni to clindamycin, gentamicin, and kanamycin, but less resistance to florfenicol. This finding demonstrated that while a particular antimicrobial may be effective for reducing C. jejuni, it may not be as effective for treating $C$. coli and vice versa. Therefore, while campylobacteriosis tends to be binned within a single category, the identification of the specific species epithet is important for treatment success. By becoming more aware of the potential differences in resistance across species epithets, properly prescribing the correct treatment regimen may further enhance antimicrobial stewardship.

\section{CONCLUSION}

Ultimately, it is poorly understood as to how fluid the Campylobacter genome is and the full risk associated with antibiotic resistance in the agricultural setting. Additionally, the link between agricultural antimicrobial abuse and treatment failures in the clinical setting still fails to be established. With increased antibiotic vigilance, research into the mechanisms that drive antibiotic resistance in Campylobacter, and the potential development of novel antimicrobial strategies, it may be possible to mitigate the effect of antibiotic resistance 
independently across the veterinary and clinical sectors. While resistance is not conferred between poultry and the clinical patient, the exposure to the clinical patient does occur through poultry. The rearrangement and transference of mobile genetic elements within the human host, the environment, and the poultry itself likely make the "smoking gun" improbable.

However, the establishment and prescription of a single-hurdle approach to control this foodborne pathogen and ultimately reduce the risk to the human population are unlikely. Therefore, not only does research need to focus on the development of new antibiotics to help patients in the clinical setting, it needs to focus on preventing the reservoir for campylobacteriosis, poultry, from continuing to serve as such. Whether or not reducing Campylobacter resistance in poultry affects the war on antibiotic resistance is unknown and will remain a mystery.

\section{REFERENCES}

Allos, B. M., and Blaser, M. J. (2010). “Campylobacter jejuni and related species” in Principles and practice of infectious diseases, 7th Edn. eds. G. L. Mandell, J. E. Bennett and R. Dolin (Philadelphia, PA: Churchill Livingstone), 2793-2802.

Bardon, J., Kolar, M., Cekanova, L., Hejnar, P., and Koukalova, D. (2009). Prevalence of Campylobacter jejuni and its resistance to antibiotics in poultry in the Czech Republic. Zoonoses Public Health 56, 111-116. doi: 10.1111/j. 1863-2378.2008.01176.x

Barnes, E. M., Mead, G., Barnuml, D., and Harry, E. (1972). The intestinal flora of the chicken in the period 2 to 6 weeks of age, with particular reference to the anaerobic bacteria. Br. Poult. Sci. 13, 311-326.

Barton, M. D. (2014). Impact of antibiotic use in the swine industry. Curr. Opin. Microbiol. 19, 9-15. doi: 10.1016/j.mib.2014.05.017

Blair, J. M., Richmond, G. E., and Piddock, L. J. (2014). Multidrug efflux pumps in Gram-negative bacteria and their role in antibiotic resistance. Future Microbiol. 9, 1165-1177. doi: 10.2217/fmb.14.66

Bolinger, H. K., Zhang, Q., Miler, W. G., and Kathariou, S. (2018). Lack of evidence for erm(B) infiltration into erythromycin-resistant Campylobacter coli and Campylobacter jejuni from commercial Turkey production in Eastern North Carolina: a major Turkey-growing region in the United States. Foorborne Pathog. Dis. 15, 1-3. doi: 10.1089/fpd.2018.2477

Casewell, M., Friis, C., Marco, E., McMullin, P., and Phillips, I. (2003). The European ban on growth-promoting antibiotics and emerging consequences for human and animal health. J. Antimicrob. Chemother. 52, 159-161. doi: $10.1093 / \mathrm{jac} / \mathrm{dkg} 313$

CDC (2019). Fast Facts 2019. Available at: https://www.cdc.gov/campylobacter/ faq.html (Accessed July 2, 2019).

Committee on Drug Use in Food Animals Panel on Animal Health, Food Safety, and Public Health (1998). Use of drugs in food animals: Benefits and risks. Washington, DC: National Academy Press.

Council for Agricultural Science and Technology (1981). Antibiotics in animal feeds. Report 88. CAST: Ames, IA.

de la Cabada Bauche, J., and DuPont, H. L. (2011). New developments in traveler's diarrhea. Gastroenterol. Hepatol. 7, 88-95.

DuPont, H. L. (2007). Azithromycin for the self-treatment of traveler's diarrhea. Clin. Infect. Dis. 44, 347-349. doi: 10.1086/510594

Eckburg, P. B., Bik, E. M., Bernstein, C. N., Purdom, E., Dethlefsen, L., Sargent, M., et al. (2005). Diversity of the human intestinal microbial flora. Science 308, 1635-1638. doi: 10.1126/science.1110591

Endtz, H. P., Ruijs, G. J., van Klingeren, B., Jansen, W. H., van der Reyden, T., and Mouton, R. P. (1991). Quinolone resistance in Campylobacter isolated from man and poultry following the introduction of fluoroquinolones in veterinary medicine. J. Antimicrob. Chemother. 27, 199-208. doi: 10.1093/ jac/27.2.199

Fridkin, S., Baggs, J., Fagan, R., Magill, S., Pollack, L. A., Malpiedi, P., et al. (2014). Vital signs: improving antibiotic use among hospitalized patients.

\section{AUTHOR CONTRIBUTIONS}

YY, KF, SR, AA, MK, and HP provided the framework and concept for the publication. YY produced the first version of the manuscript. KF completed, edited, and restructured the manuscript for publication. KF submitted the manuscript and handled all communications with the reviewers. All authors reviewed the manuscript prior to submission.

\section{FUNDING}

YY, KF, MK, and SR were not provided financial assistance to complete this review. HP is an employee of Diamond V Mills (Cedar Rapids, IA, USA).

MMWR Morb. Mortal. Wkly. Rep. 63, 194-200. https://www.cdc.gov/mmwr/ preview/mmwrhtml/mm6309a4.html.

Frost, I., Van Boeckel, T. P., Pires, J., Craig, J., and Laxminarayan, R. (2019). Global geographic trends in antimicrobial resistance: the role in internaitonal travel. J. Travel Med. doi: 10.1093/jtm/taz036

Galdiero, S., Falanga, A., Cantisani, M., Tarallo, R., Elena Della Pepa, M., D'Oriano, V., et al. (2012). Microbe-host interactions: structure and role of Gram-negative bacterial porins. Curr. Protein Pept. Sci. 13, 843-854. doi: $10.2174 / 138920312804871120$

Gallay, A., Prouzet-Mauléon, V., Kempf, I., Lehours, P., Labadi, L., Camou, C., et al. (2007). Campylobacter antimicrobial drug resistance among humans, broiler chickens, and pigs, France. Emerg. Infect. Dis. 13, 259-266. doi: 10.3201/eid1302.060587

Gibreel, A., Sjögren, E., Kaijser, B., Wretlind, B., and Sköld, O. (1998). Rapid emergence of high-level resistance to quinolones in Campylobacter jejuni associated with mutational changes in gyrA and parC. Antimicrob. Agents Chemother. 42, 3276-3278. doi: 10.1128/AAC.42.12.3276

Guerrant, R. L., Van Gilder, T., Steiner, T. S., Thielman, N. M., Slutsker, L., Tauxe, R. V., et al. (2001). Practice guidelines for the management of infectious diarrhea. Clin. Infect. Dis. 32, 331-351. doi: 10.1086/318514

Gupta, A., Nelson, J. M., Barrett, T. J., Tauxe, R. V., Rossiter, S. P., Friedman, C. R., et al. (2004). Antimicrobial resistance among Campylobacter strains, United States, 1997-2001. Emerg. Infect. Dis. 10, 1102-1109. doi: 10.3201/ eid1006.030635

Handzlik, J., Matys, A., and Kieć-Kononowicz, K. (2013). Recent advances in multi-drug resistance (MDR) efflux pump inhibitors of Gram-positive bacteria S. aureus. Antibiotics 2, 28-45. doi: 10.3390/antibiotics2010028

Hao, H., Ren, N., Han, J., Foley, S. L., Iqbal, Z., Cheng, G., et al. (2016). Virulence and genomic feature of multidrug resistant Campylobacter jejuni isolated from broiler chicken. Front. Microbiol. 7:1605. doi: 10.3389/ fmicb.2016.01605

Hoge, C. W., Gambel, J. M., Srijan, A., Pitarangsi, C., and Echeverria, P. (1998). Trends in antibiotic resistance among diarrheal pathogens isolated in Thailand over 15 years. Clin. Infect. Dis. 26, 341-345. doi: 10.1086/516303

Hurd, H. S., Doores, S., Hayes, D., Mathew, A., Maurer, J., Silley, P., et al. (2004). Public health consequences of macrolide use in food animals: a deterministic risk assessment. J. Food Prot. 67, 980-992. doi: 10.4315/0362-028X-67.5.980

Hussein, K., Raz-Pasteur, A., Schachor-Meyouhas, Y., Geffen, Y., Oren, I., and Kassis, I. (2016). Campylobacter bacteraemia: 16 years of experience in a single centre. Infect. Dis. 46, 796-799. doi: 10.1080/23744235.2016.1195916

Iovine, N. M. (2013). Resistance mechanisms in Campylobacter jejuni. Virulence 4, 230-240. doi: 10.4161/viru.23753

Jain, D., Sinha, S., Prasad, K. N., and Pandey, C. M. (2005). Campylobacter species and drug resistance in north Indian rural community. Trans. $R$. Soc. Trop. Med. Hyg. 99, 207-214. doi: 10.1016/j.trstmh.2004.09.006

Kojima, C., Kishimoto, M., and Ezaki, T. (2015). Distribution of antimicrobial resistance in Campylobacter strains isolated from poultry at a slaughterhouse and supermarkets in Japan. Biocontrol Sci. 20, 179-184. doi: 10.4265/bio.20.179 
Kuschner, R. A., Trofa, A. F., Thomas, R. J., Hoge, C. W., Pitarangsi, C., Amato, S., et al. (1995). Use of azithromycin for the treatment of Campylobacter enteritis in travelers to Thailand, an area where ciprofloxacin resistance is prevalent. Clin. Infect. Dis. 21, 536-541. doi: 10.1093/clinids/21.3.536

Lehtopolku, M., Nakari, U.-M., Kotilainen, P., Huovinen, P., Siitonen, A., and Hakanen, A. J. (2010). Antimicrobial susceptibilities of multidrug-resistant Campylobacter jejuni and C. coli strains: in vitro activities of 20 antimicrobial agents. Antimicrob. Agents Chemother. 54, 1232-1236. doi: 10.1128/AAC.00898-09

Li, B., Ma, L., Li, Y., Jia, H., Wei, J., Shao, D., et al. (2017). Antimicrobial resistance of Campylobacter species isolated from broilers in live bird markets in Shanghai, China. Foodborne Pathog. Dis. 14, 96-102. doi: 10.1089/fpd.2016.2186

Lin, J., Yan, M., Sahin, O., Pereira, S., Chang, Y.-J., and Zhang, Q. (2007). Effect of macrolide usage on emergence of erythromycin-resistant Campylobacter isolates in chickens. Antimicrob. Agents Chemother. 51, 1678-1686. doi: 10.1128/AAC.01411-06

Ling, J., Chan, E., Lam, A., and Cheng, A. (2003). Mutations in topoisomerase genes of fluoroquinolone-resistant salmonellae in Hong Kong. Antimicrob. Agents Chemother. 47, 3567-3573. doi: 10.1128/AAC.47.11.3567-3573.2003

Luber, P., Wagner, J., Hahn, H., and Bartelt, E. (2003). Antimicrobial resistance in Campylobacter jejuni and Campylobacter coli strains isolated in 1991 and 2001-2002 from poultry and humans in Berlin, Germany. Antimicrob. Agents Chemother. 47, 3825-3830. doi: 10.1128/AAC.47.12.3825-3830.2003

Mäesaar, M., Kramarenko, T., Meremäe, K., Sõgel, J., Lillenberg, M., Häkkinen, L., et al. (2016). Antimicrobial resistance profiles of Campylobacter spp. isolated from broiler chicken meat of Estonian, Latvian and Lithuanian origin at Estonian retail level and from patients with severe enteric infections in Estonia. Zoonoses Public Health 63, 89-96. doi: 10.1111/zph.12208

Mamelli, L., Amoros, J.-P., Pagès, J.-M., and Bolla, J.-M. (2003). A phenylalaninearginine $\beta$-naphthylamide sensitive multidrug efflux pump involved in intrinsic and acquired resistance of Campylobacter to macrolides. Int. J. Antimicrob. Agents 22, 237-241. doi: 10.1016/S0924-8579(03)00199-7

McCormick, B. J. J., and Lang, D. R. (2016). Diarrhea disease and enteric infections in LMIC communities: how big is the problem? Trop. Dis. Travel Med. Vaccines 2. doi: 10.1186/s40794-016-0028-7

Meng, C. Y., Smith, B. L., Bodhidatta, L., Richard, S. A., Vansith, K., Thy, B., et al. (2011). Etiology of diarrhea in young children and patterns of antibiotic resistance in Cambodia. Pediatr. Infect. Dis. J. 30, 331-335. doi: 10.1097/ INF.0b013e3181fb6f82

Nannapaneni, R., Story, R., Wiggins, K. C., and Johnson, M. G. (2005). Concurrent quantitation of total Campylobacter and total ciprofloxacin-resistant Campylobacter loads in rinses from retail raw chicken carcasses from 2001 to 2003 by direct plating at 42 C. Appl. Environ. Microbiol. 71, 4510-4515. doi: 10.1128/AEM.71.8.4510-4515.2005

Nikaido, H., and Pagès, J.-M. (2012). Broad-specificity efflux pumps and their role in multidrug resistance of Gram-negative bacteria. FEMS Microbiol. Rev. 36, 340-363. doi: 10.1111/j.1574-6976.2011.00290.x

Nord, C., and Edlund, C. (1991). Ecological effects of antimicrobial agents on the human intestinal microflora. Microb. Ecol. Health Dis. 4, 193-207.

Norris, A. L., and Serpersu, E. H. (2013). Ligand promiscuity through the eyes of the aminoglycoside N3 acetyltransferase IIa. Protein Sci. 22, 916-928. doi: $10.1002 /$ pro.2273

Ohishi, T., Aoki, K., Ishii, Y., Usui, M., Tamura, Y., Kawanishi, M., et al. (2017). Molecular epidemiological analysis of human-and chicken-derived isolates of Campylobacter jejuni in Japan using next-generation sequencing. J. Infect. Chemother. 23, 165-172. doi: 10.1016/j.jiac.2016.11.011

Olaiya, D., Fok, R., Chakrabarti, P., Sharma, H., and Greig, J. (2018). Campylobacter fetus spondylodiscitis: A case report and review of the literature. IDCases e00468. doi: 10.1016/j.idcr.2018.e00468

Page, W. J., Huyer, G., Huyer, M., and Worobec, E. (1989). Characterization of the porins of Campylobacter jejuni and Campylobacter coli and implications for antibiotic susceptibility. Antimicrob. Agents Chemother. 33, 297-303. doi: 10.1128/AAC.33.3.297

Pagès, J.-M., and Amaral, L. (2009). Mechanisms of drug efflux and strategies to combat them: challenging the efflux pump of Gram-negative bacteria. Biochim. Biophys. Acta 1794, 826-833. doi: 10.1016/j.bbapap.2008.12.011

Pandey, P., Bodhidatta, L., Lewis, M., Murphy, H., Shlim, D. R., Cave, W., et al. (2010). Travelers' diarrhea in Nepal: an update on the pathogens and antibiotic resistance. J. Travel Med. 18, 102-108. doi: 10.1111/j.17088305.2010.00475.x
Payot, S., Avrain, L., Magras, C., Praud, K., Cloeckaert, A., and Chaslus-Dancla, E. (2004). Relative contribution of target gene mutation and efflux to fluoroquinolone and erythromycin resistance, in French poultry and pig isolates of Campylobacter coli. Int. J. Antimicrob. Agents 23, 468-472. doi: 10.1016/j.ijantimicag.2003.12.008

Phillips, I., Casewell, M., Cox, T., DeGroot, B., Friis, C., Jones, R., et al. (2004). Does the use of antibiotics in food animals pose a risk to human health? A critical review of published data. J. Antimicrob. Chemother. 53, 28-52. doi: $10.1093 / \mathrm{jac} / \mathrm{dkg} 483$

Pollett, S., Rocha, C., Zerpa, R., Patiño, L., Valencia, A., Camiña, M., et al. (2012). Campylobacter antimicrobial resistance in Peru: a ten-year observational study. BMC Infect. Dis. 12:193. doi: 10.1186/1471-2334-12-193

Pumbwe, L., Randall, L. P., Woodward, M. J., and Piddock, L. J. (2004), Expression of the efflux pump genes $c m e B, c m e F$ and the porin gene porA in multiple-antibiotic-resistant Campylobacter jejuni. J. Antimicrob. Chemother. 54, 341-347. doi: 10.1093/jac/dkh331

Raeisi, M., Khoshbakht, R., Ghaemi, E. A., Bayani, M., Hashemi, M., Seyedghasemi, N. S., et al. (2017). Antimicrobial resistance and virulenceassociated genes of Campylobacter spp. isolated from raw milk, fish, poultry, and red meat. Microb. Drug Resist. 23, 925-933. doi: 10.1089/mdr.2016.0183

Salazar-Lindo, E., Sack, R. B., Chea-Woo, E., Kay, B. A., Piscoya, Z. A., Leon-Barua, R., et al. (1986). Early treatment with erythromycin of Campylobacter jejuni-associated dysentery in children. J. Pediatr. 109, 355-360. doi: 10.1016/S0022-3476(86)80404-8

Sanders, J. W., Frenck, R. W., Putnam, S. D., Riddle, M. S., Johnston, J. R., Ulukan, S., et al. (2007). Azithromycin and loperamide are comparable to levofloxacin and loperamide for the treatment of traveler's diarrhea in United States military personnel in Turkey. Clin. Infect. Dis. 45, 294-301. doi: 10.1086/519264

Segreti, J., Gootz, T. D., Goodman, L. J., Parkhurst, G. W., Quinn, J. P., Martin, B. A., et al. (1992). High-level quinolone resistance in clinical isolates of Campylobacter jejuni. J. Infect. Dis. 165, 667-670. doi: 10.1093/infdis/165.4.667

Silva, D. T., Tejada, T. S., Blum-Menezes, D., Dias, P. A., and Timm, C. D. (2016). Campylobacter species isolated from poultry and humans, and their analysis using PFGE in southern Brazil. Int. J. Food Microbiol. 217, 189-194. doi: 10.1016/j.ijfoodmicro.2015.10.025

Sjögren, E., Lindblom, G., and Kaijser, B. (1997). Norfloxacin resistance in Campylobacter jejuni and Campylobacter coli isolates from Swedish patients. J. Antimicrob. Chemother. 40, 257-261. doi: 10.1093/jac/40.2.257

Smith, K. E., Besser, J. M., Hedberg, C. W., Leano, F. T., Bender, J. B., Wicklund, J. H., et al. (1999). Quinolone-resistant Campylobacter jejuni infections in Minnesota, 1992-1998. N. Engl. J. Med. 340, 1525-1532. doi: 10.1056/NEJM199905203402001

Tang, Y., Dai, L., Sahin, O., Wu, Z., Liu, M., and Zhang, Q. (2017). Emergence of a plasmid-borne multidrug resistance gene $c f r(\mathrm{C})$ in foodborne pathogen Campylobacter. J. Antimicrob. Chemother. 72, 1581-1588. doi: 10.1093/jac/dkx023

Taylor, N., Davies, R., Ridley, A., Clouting, C., Wales, A., and Clifton-Hadley, F. (2008). A survey of fluoroquinolone resistance in Escherichia coli and thermophilic Campylobacter spp. on poultry and pig farms in Great Britain. J. Appl. Microbiol. 105, 1421-1431. doi: 10.1111/j.1365-2672.2008.03877.x

Thakur, S., Zhao, S., McDermott, P. F., Harbottle, H., Abbott, J., English, L., et al. (2010). Antimicrobial resistance, virulence, and genotypic profile comparison of Campylobacter jejuni and Campylobacter coli isolated from humans and retail meats. Foodborne Pathog. Dis. 7, 835-844. doi: 10.1089/ fpd.2009.0487

Toledo, Z., Simaluiza, R. J., and Fernandez, H. (2018). Occurance and antibiotic resistance of Campylobacter jejuni and Campylobacter coli from domestic animals from Southern Ecuador. Microbiology 48:e20180003. doi: 10.1590/0103$8478 \mathrm{cr} 20180003$

US Food and Drug Administration (2014). NARMS integrated report: 2014. The National Antimicrobial Resistance Monitoring System (NARMS): Enteric bacteria. Silver Spring, MD: US Food and Drug Administration. https://www.fda.gov/ downloads/AnimalVeterinary/SafetyHealth/AntimicrobialResistance/ NationalAntimicrobialResistanceMonitoringSystem/UCM528861.pdf

Van Boeckel, T. P., Brower, C., Gilbert, M., Grenfell, B. T., Levin, S. A., Robinson, T. P., et al. (2014). Global trends in antimicrobial use in food animlas. PNAS 112, 5649-5654. doi: 10.1073/pnas.1503141112

Vaughn, M. B., and Copeland, D. (2004). "Is there human health harm following fluoroquinolone use in poultry?" in Proceedings of the 53rd Western Poultry Disease Conference, Sacramento, CA. 27-29. 
Ventola, C. L. (2015a). The antibiotic resistance crisis: part 1: causes and threats. Phar. Ther. 40, 277-283.

Ventola, C. L. (2015b). The antibiotic resistant crisis, part 2: management strategies and new agents. Phar. Ther. 40, 344-352.

Veterinary Feed Directive (VFD) (2017). FDA. Available at: https://www.fda. gov/animal-veterinary/development-approval-process/veterinary-feed-directivevfd (Accessed July 2, 2019).

Vetting, M. W., Hegde, S. S., Wang, M., Jacoby, G. A., Hooper, D. C., and Blanchard, J. S. (2011). Structure of QnrB1, a plasmid-mediated fluoroquinolone resistance factor. J. Biol. Chem. doi: 10.1074/jbc.M111.226936

Vukelic, D., Trkulja, V., and Salkovic-Petrisic, M. (2010). Single oral dose of azithromycin versus 5 days of oral erythromycin or no antibiotic in treatment of Campylobacter enterocolitis in children: a prospective randomized assessorblind study. J. Pediatr. Gastroenterol. Nutr. 50, 404-410. doi: 10.1097/ MPG.0b013e3181a87104

Wagner, J., Jabbusch, M., Eisenblätter, M., Hahn, H., Wendt, C., and Ignatius, R. (2003). Susceptibilities of Campylobacter jejuni isolates from Germany to ciprofloxacin, moxifloxacin, erythromycin, clindamycin, and tetracycline. Antimicrob. Agents Chemother. 47, 2358-2361. doi: 10.1128/AAC.47.7.2358-2361.2003

Wegener, H. C. (2003). Antibiotics in animal feed and their role in resistance development. Curr. Opin. Microbiol. 6, 439-445. doi: 10.1016/j. mib.2003.09.009

WHO (2014). Antimicrobial resistance: Global report on surveillance. Geneva, Switzerland: World Health Organization.

Wieczorek, K., Denis, E., Lachtara, B., and Osek, J. (2017). Distribution of Campylobacter jejuni multilocus sequence types isolated from chickens in Poland. Poult. Sci. 96, 703-709. doi: 10.3382/ps/pew343

Wieczorek, K., Wołkowicz, T., and Osek, J. (2018). Antimicrobial resistance and virulence-associated traits of Campylobacter jejuni isolated from poultry food chain and humans with diarrhea. Front. Microbiol. 9:1508. doi: 10.3389/ fmicb. 2018.01508

Wretlind, B., Strömberg, A., Östlund, L., Sjögren, E., and Kaijser, B. (1992). Rapid emergence of quinolone resistance in Campylobacter jejuni in patients treated with norfloxacin. Scand. J. Infect. Dis. 24, 685-686.
Yan, M., Sahin, O., Lin, J., and Zhang, Q. (2006). Role of the CmeABC efflux pump in the emergence of fluoroquinolone-resistant Campylobacter under selection pressure. J. Antimicrob. Chemother. 58, 1154-1159. doi: 10.1093/ jac/dkl412

Yao, H., Shen, Z., Wang, Y., Deng, F., Liu, D., Naren, G., et al. (2016). Emergence of a potent multidrug efflux pump variant that enhances Campylobacter resistance to multiple antibiotics. MBio 7, e01543-e01516. doi: 10.1128/ mBio.01543-16

Zhao, S., McDermott, P. F., Friedman, J., Abbot, S., Ayers Glenn, A., Hall-Robinson, E., et al. (2006). Antimicrobial resistance and genetic relatedness among Salmonella from retail foods of animal origin: NARMs retail meat surveillance. Foodborne Pathog. Dis. 3, 106-117. doi: 10.1089/fpd.2006.3.106

Zhao, S., Mukherjee, S., Chen, Y., Li, C., Young, S., Warren, M., et al. (2015). Novel gentamicin resistance genes in Campylobacter isolated from humans and retail meats in the USA. J. Antimicrob. Chemother. 70, 1314-1321. doi: 10.1093/jac/dkv001

Zhao, S., Young, S., Tong, E., Abbott, J., Womack, N., Friedman, S., et al. (2010). Antimicrobial resistance of Campylobacter isolates from retail meat in the United States between 2002 and 2007. Appl. Environ. Microbiol. 76, 7949-7956. doi: 10.1128/AEM.01297-10

Conflict of Interest Statement: HP is an employee of Diamond V.

The remaining authors declare that the research was conducted in the absence of any commercial or financial relationships that could be construed as a potential conflict of interest.

Copyright (C) 2019 Yang, Feye, Shi, Pavlidis, Kogut, Ashworth and Ricke. This is an open-access article distributed under the terms of the Creative Commons Attribution License (CC BY). The use, distribution or reproduction in other forums is permitted, provided the original author(s) and the copyright owner(s) are credited and that the original publication in this journal is cited, in accordance with accepted academic practice. No use, distribution or reproduction is permitted which does not comply with these terms. 